\title{
Identification of quantitative trait loci associated with bone traits and body weight in an $\mathbf{F} 2$ resource population of chickens*
}

\author{
Melissa A. SchreIWEIS, Patricia Y. HESTER, Diane E. MoodY** \\ Department of Animal Sciences, Purdue University, West Lafayette, IN, USA
}

(Received 1 March 2005; accepted 5 July 2005)

\begin{abstract}
Bone fractures at the end of lay are a significant problem in egg-laying strains of hens. The objective of the current study was to identify quantitative trait loci (QTL) associated with bone mineralization and strength in a chicken resource population. Layer (White Leghorn hens) and broiler (Cobb-Cobb roosters) lines were crossed to generate an F2 population of 508 hens over seven hatches, and 26 traits related to bone integrity, including bone mineral density (BMD) and content (BMC), were measured. Genotypes of 120 microsatellite markers on 28 autosomal groups were determined, and interval mapping was conducted to identify QTL regions. Twenty-three tests representing three chromosomal regions (chromosomes 4, 10 and 27) contained significant QTL that surpassed the 5\% genome-wise threshold, and 47 tests representing 15 chromosomes identified suggestive QTL that surpassed the 5\% chromosome-wise threshold. Although no significant QTL influencing BMD and BMC were detected after adjusting for variation in body weight and egg production, multiple suggestive QTL were found. These results support previous experiments demonstrating an important genetic regulation of bone strength in chickens, but suggest the regulation may be due to the effects of multiple genes that each account for relatively small amounts of variation in bone strength.
\end{abstract}

bone mineral density / chickens / QTL / osteoporosis

\section{INTRODUCTION}

Osteoporosis is a progressive loss in structural bone and is a common problem in caged egg-laying strains of hens [60]. Welfare issues associated with osteoporosis have become more urgent due to the increasing use of battery cages, which contributes to a decrease in structural bone, leading to bone fragility and

\footnotetext{
* Journal Paper No. 2004-17471 of the Purdue University Agricultural Research Programs, West Lafayette, IN, USA.

${ }^{* *}$ Corresponding author: moodyd@iastate.edu

Present address: Department of Animal Science, Iowa State University, Ames, IA, USA.
} 
susceptibility to fracture $[2,13,60]$. It has been estimated that bone fragility is responsible for $35 \%$ of hen mortalities in caged systems [33], and bone fractures due to production, handling, and transportation have been reported in $29 \%$ of birds that reach processing facilities [15] and $98 \%$ of birds by the end of the processing line [3]. Thus, in addition to animal welfare concerns, osteoporosis causes economic loss in the egg-laying industry due to hen mortality and a loss of a market for spent hens.

It is well established that environmental factors such as dietary calcium and the ability to exercise influence bone strength [18, 22, 29, 38]. Additionally, variation in bone strength is influenced by genetics, with heritability estimated as 0.40 [4]. Mandour et al. [32] demonstrated an increase in humerus strength following three generations of selection in a population of broilers, where selection was based on an index of bone traits measured in progeny. Similarly, Bishop et al. [4] reported a 2-fold improvement of bone strength in chickens after seven generations of divergent selection for a bone index. Although these selection experiments demonstrate that improvements in bone integrity can be made through genetic selection, they rely on measurement of traits that require euthanasia of the bird. As an alternative, our lab validated the use of dualenergy X-ray absorptiometry (DEXA) as a non-invasive tool for measurement of bone mineral density (BMD) and content (BMC) in live birds [41, 43]. Although DEXA is effective at measuring differences in bone strength among birds, it is also a time consuming and labor intensive process. These limitations of DEXA could be overcome if genetic markers for BMD and BMC are identified and incorporated into marker-assisted selection programs. Thus, the objective of this study was to investigate the genetic regulation of bone traits in chickens by conducting a genome scan for quantitative trait loci (QTL) influencing BMD, BMC, and traditional measurements of bone strength. Development of genetic markers for these traits will contribute to the improvement of bone integrity in chickens through marker assisted selection for increased bone strength.

\section{MATERIALS AND METHODS}

\subsection{Comparison of $\mathrm{BMD}$ and $\mathrm{BMC}$}

Differences in BMD and BMC between layer and broiler lines were determined by measuring BMD and BMC of the tibia (methods described below) in 19 to 47 broiler and 31 to 35 Leghorn females at 10-wk intervals between 15 and 65 wk of age. Hens used for this comparison represented the same genetic 
lines as the founders of the F2 resource population, and were raised together under standard management conditions.

\subsection{Resource populations}

An F2 resource population was generated from 16 hens representing a Hyline White Leghorn primary breeding stock line, and 5 roosters from a commercial strain of Cobb-Cobb broilers. To generate the F2 population, 15 F1 roosters were each mated to two unrelated females, producing a total of 508 hens over seven hatches occurring at two-week intervals, as illustrated in Figure 1. The complete resource population included 21 grandparents, $45 \mathrm{~F} 1$ parents, and 508 F2 hens. One-day-old F2 chicks were housed in wire cages with 8 chicks per cage, providing $465 \mathrm{~cm}^{2}$ per bird. Chicks were fed a starter diet from 0 to $5 \mathrm{wk}$, a grower diet from 6 to $7 \mathrm{wk}$, a developer diet from 8 to $14 \mathrm{wk}$, and a pre-lay diet from 15 to $17 \mathrm{wk}$ of age. Compositions of these diets have been published previously [43] and included $0.90 \%, 0.81 \%, 0.72 \%$, and $2.62 \%$ calcium, respectively. At 17 wk of age, each bird was transferred to an individual laying cage $\left(1084 \mathrm{~cm}^{2} /\right.$ bird $)$ and at $18 \mathrm{wk}$ of age each bird was photo-stimulated and fed a breeder diet $\left(1295 \mathrm{kcal} \cdot \mathrm{kg}^{-1}\right.$ metabolizable energy; $16.03 \%$ crude protein; $0.46 \%$ non-phytate phosphorus; and $2.98 \%$ calcium). Feed intake was restricted based on average bi-weekly body weight of each hatch, beginning when the hens reached 6 to 16 wk of age (Fig. 1). A batch of feed containing no limestone $(1.0 \% \mathrm{Ca})$ was unintentionally fed for $12 \mathrm{~d}$ during the experiment. This occurred at different ages for the seven hatches, as illustrated in Figure 1.

\subsection{Measurement of phenotypes}

Traits of primary interest were BMD and BMC, which were measured on the left leg (tibia and fibula) and wing (humerus) at 35 and 55 wk of age. Measurement of BMD and BMC by a densitometric scan using DEXA (Model No. 476D014; Norland Medical Systems, Fort Atkinson, WI) has been described and validated previously [41-43]. Using the densitometric scans, length of the bone was measured from the proximal to distal end of the bone, and width of the bone was measured at half of the length. These measurements were analyzed as individual traits, and used to adjust BMC for size of the bone, giving BMD in units of $\mathrm{g} \cdot \mathrm{cm}^{-2}$. Individual BW was recorded at the time of each bone scan. Traditional measurements of bone breaking strength were taken at $60 \mathrm{wk}$. Birds were euthanized using carbon dioxide, the tibia was excised 


\begin{tabular}{|l|l|l|l|l|l|l|l|l|l|l|l|l|l|l|l|l|l|}
\hline \multicolumn{2}{|c|}{2002} & \multicolumn{10}{|c|}{2003} & \multicolumn{4}{|c|}{2004} \\
\hline \hline Nov & Dec & Jan & Feb & Mar & Apr & May & Jun & Jul & Aug & Sep & Oct & Nov & Dec & Jan & Feb & Mar & Apr \\
\hline
\end{tabular}

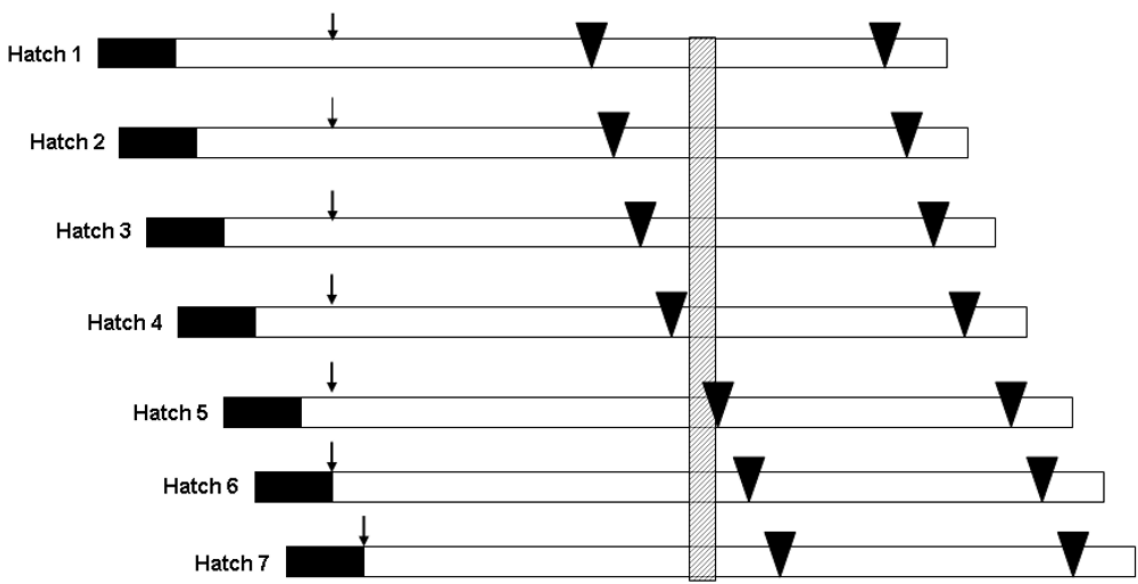

Figure 1. Timeline of data collection and management of F2 population. All bone scans were conducted at 35 and 55 wk of age using a Norland pDexa X-ray bone densitometer, as specified by black triangles. Body weight was measured weekly through 6 weeks of age, as indicated by the solid black box. Feed restriction based on average bi-weekly hatch weights was initiated at different ages, as indicated by black arrows. A batch of feed that was deficient in limestone was fed for 12 days, as indicated by the shaded bar. Hens were euthanized at 60 weeks of age, and the right tibia was collected for traditional measurements of bone strength.

and wrapped in $0.85 \%$ saline-soaked gauze and frozen at $-7{ }^{\circ} \mathrm{C}$ until analysis of bone traits, as described previously [41]. Bone stress, strain, and modulus of elasticity were calculated as described previously [10]. A complete list of phenotypes evaluated and their units of measurement is provided in Table I. Additionally, individual egg production was recorded from the time birds were placed in laying cages $(17 \mathrm{wk})$ until the experiment was terminated.

\subsection{Genotyping}

Genomic DNA was extracted from whole blood using a standard proteinase $\mathrm{K}$, salting out, and ethanol precipitation protocol. A total of 120 microsatellite markers was selected from a set of 147 markers of the Comprehensive Mapping Kit \#7 supplied by the US Poultry Genome Coordinators (http://poultry.mph.msu.edu). Selection of markers was based on optimization for PCR and level of polymorphism in the grandparent population. Individual 
PCR for all microsatellite markers were performed in a reaction containing $50 \mathrm{ng}$ genomic DNA, $190 \mathrm{nM}$ forward and reverse primers, and 2.5X Eppendorf MasterMix (Brinkmann Instruments, Inc., Westbury, NY) in a total reaction volume of $20 \mu \mathrm{l}$. Thermal cycling conditions for all primers in degrees centigrade were: $95^{\circ}$ for $5 \mathrm{~min} ; 95^{\circ}$ for $45 \mathrm{~s}, 68^{\circ}$ to $60^{\circ}$ for $45 \mathrm{~s}, 72^{\circ}$ for $1 \mathrm{~min}$ ( 5 cycles with annealing temperatures dropping $2^{\circ}$ per cycle); $95^{\circ}$ for $45 \mathrm{~s}, 58^{\circ}$ for $2 \mathrm{~min}, 72^{\circ}$ for $1 \mathrm{~min} ; 95^{\circ}$ for $45 \mathrm{~s}, 56^{\circ}$ for $2 \mathrm{~min}, 72^{\circ}$ for $1 \mathrm{~min} ; 95^{\circ}$ for $45 \mathrm{~s}, 54^{\circ}$ for $2 \mathrm{~min}, 72^{\circ}$ for $1 \mathrm{~min}$ ( 33 cycles); $72^{\circ}$ for $10 \mathrm{~min}$. Genotyping was completed using an ABI 3700 DNA Analyzer, Genescan Analysis Software, and Genotyper v3.6 NT (Applied Biosysems, Foster City, CA).

\subsection{Data analysis}

The BMD at 6 ages ( 15 to $65 \mathrm{wk}$ ) of hens representing the grandparent lines were analyzed as a split plot with repeated measures using a mixed model $\left(\mathrm{SAS}^{\circledR}[40]\right)$ with strain of bird included a fixed effect, and BW as a covariate. The whole plot was the strain of bird in which the tibial BMD of the broiler and Leghorn were compared. Differences of least square means were used to partition means for significant interactions. Phenotypic correlations among traits in the $\mathrm{F} 2$ population were determined using the CORR procedure in $\mathrm{SAS}{ }^{\circledR}$ [40]. Linkage analyses were performed using Crimap version 2.4 [14] with distances reported in Kosambi cM units. Informativeness of markers was assessed as previously described [28] and was calculated using QTL Express software [45].

The QTL analysis was performed using the F2 least squares interval mapping method and the QTL Express software program [45]. Hatch (1-7) was included as a fixed effect in the model for all traits. To identify covariates for the QTL analysis, linear and quadratic effects of body weight and cumulative egg production on bone traits were evaluated using the GLM procedure of SAS ${ }^{\circledR}$ [40]. Body weight and cumulative egg production at the time of measurement were included in the QTL analysis as linear covariates for 35 and $55 \mathrm{wk}$ BMD and BMC. Body weight at $58 \mathrm{wk}$ was included as linear and quadratic covariates for bone breaking force at $60 \mathrm{wk}$. Six chromosomes contained one marker per chromosome and were evaluated by analyzing QTL genotype probabilities at the marker, as generated by QTL Express, by analysis

of variance using the GLM procedure of SAS ${ }^{\circledR}$ [40]. Birds that were molting and not laying eggs before $55 \mathrm{wk}$ of age $(n=39)$ were omitted from the analyses for bone traits at 55 and $60 \mathrm{wk}$ of age. Test statistics for QTL effects, calculated as an F-ratio, were determined at $1 \mathrm{cM}$ intervals across the linkage map. Additive and dominance effects were estimated for each putative QTL 
using the same fixed effects and covariates as previously described. The percent of phenotypic variance explained by significant QTL was calculated as percent difference in the residual sums of squares between the full and reduced model.

Significance thresholds were determined by permutation testing [9] using QTL Express. Suggestive QTL were defined as those with an F-ratio statistic greater than the highest $5 \%$ generated by chromosome-wise permutation testing using 10000 permutations. Genome-wise significance was determined for each trait by conducting 1000 permutations over all chromosomes. Significant QTL were defined by an F ratio greater than the 5\% genome-wise threshold. The genome-wise permutation threshold was used to determine significance of the single marker chromosomes. Confidence intervals of estimates of QTL position were defined using the bootstrap procedure [58], based on 1000 samples.

\section{RESULTS}

\subsection{Description of phenotypes}

At 15 and 25 wk of age, differences in BMD between layer and broiler hens were not significant $(P>0.05)$. However, tibial BMD diverged following the onset of sexual maturity (20 to $30 \mathrm{wk}$ ) such that BMD of broiler hens was significantly greater than that of Leghorn hens from 35 to $65 \mathrm{wk}$ of age $(P<0.001$; Fig. 2).

A summary of traits observed in the $\mathrm{F}_{2}$ population is provided in Table $\mathrm{I}$. The BMD of the tibia and humerus at 35 and $55 \mathrm{wk}$ of age had high positive phenotypic correlations with their respective $\mathrm{BMC}(r=0.91$ to $0.93, P<0.001)$, and correlations among BMD and BMC measurements of the tibia and humerus at 35 and 55 wk of age were also significant $(P<0.0001)$. Positive phenotypic correlations of BW with BMD and BMC of the humerus $(r=0.32$ to 0.58 , $P<0.001)$ and tibia $(r=0.40$ to $0.73, P<0.001)$ were also observed. Tibia breaking force at $60 \mathrm{wk}$ of age was positively correlated with BW at 35 and 55 wk of age $(r=0.42$ and 0.56 , respectively, $P<0.001)$, as well as with $\mathrm{BMD}$ and BMC measured at 35 and $55 \mathrm{wk}$ of age ( $r=0.28$ to 0.74$)$.

\subsection{QTL results}

Marker order in the $\mathrm{F}_{2}$ population was conserved in our population as compared to the published chicken genetic linkage map [17]. However, four markers (ADL0019, ADL0020, ADL0037, and ADL0248) were found to be unlinked 


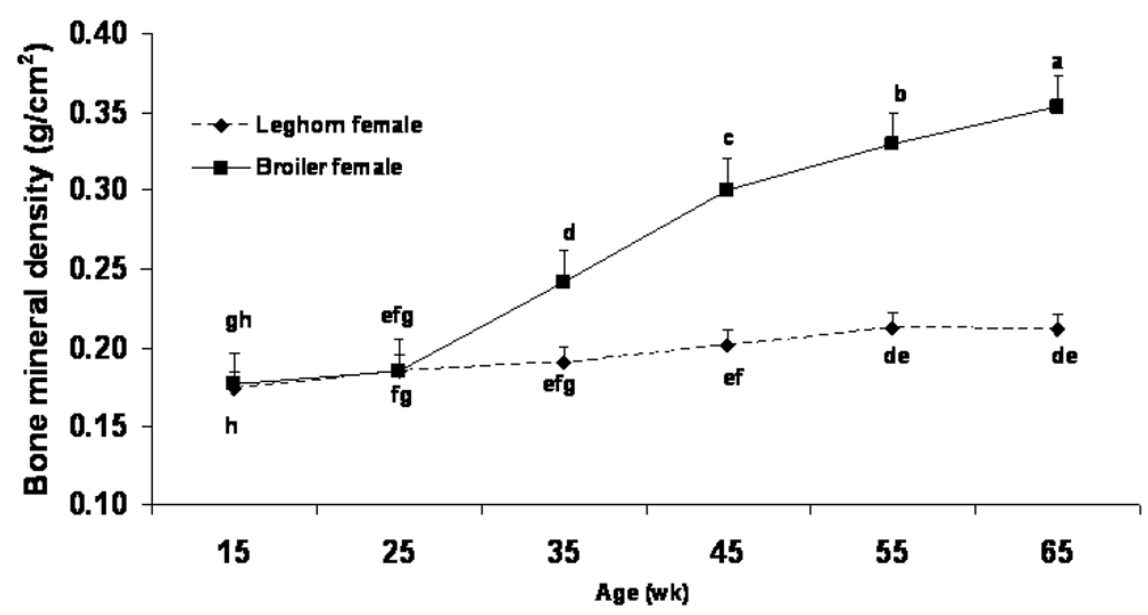

Figure 2. Tibia bone mineral density of broiler and Leghorn grandparent lines from 15 to 65 wk of age, adjusted for body weight. ${ }^{\text {a-h }}$ Least square means \pm SEM with different superscripts are significantly different (strain $\times$ age interaction, $P<0.001$ ). Means represent 19 to 47 and 31 to 35 observations for the broiler and leghorn strains per age, respectively.

to other markers in our population and omitted from further analyses. Average marker informativeness and genome coverage for each chromosome are presented in Table II. Average distance between markers was 24.8 Kosambi cM and the total genome size estimated from the linkage analysis was $3018 \mathrm{cM}$, including an arbitrary $30 \mathrm{cM}$ for each single marker chromosome.

Eight QTL tests surpassed the 5\% chromosome-wise significance threshold for a BMD measurement (humerus and tibia at 35 and $55 \mathrm{wk}$; Tab. III), but no BMD QTL were significant at the 5\% genome-wise level. The broiler allele of QTL on chromosomes 3, 6, 15, and 26 was associated with increased bone strength, while the layer allele of the QTL on chromosome 17 was associated with greater BMD. Three of the QTL (chromosomes 2, 6, and 27) also appeared to have important dominance effects. Nine QTL tests surpassed the 5\% chromosome-wise significance threshold for a BMC measurement (humerus and tibia at 35 and $55 \mathrm{wk}$; Tab. III), but no BMC QTL were significant at the $5 \%$ genome-wise level. The broiler allele of each of these QTL was associated with greater BMC, except that QTL for TBMC on chromosomes 2, 7 and 11 appeared to result primarily from dominant gene action. Two chromosomal regions (chromosomes 2 and 27) contained suggestive QTL for at least one measurement of BMD or BMC at both 35 and $55 \mathrm{wk}$, while the remaining QTL regions influenced these traits at only one age. 


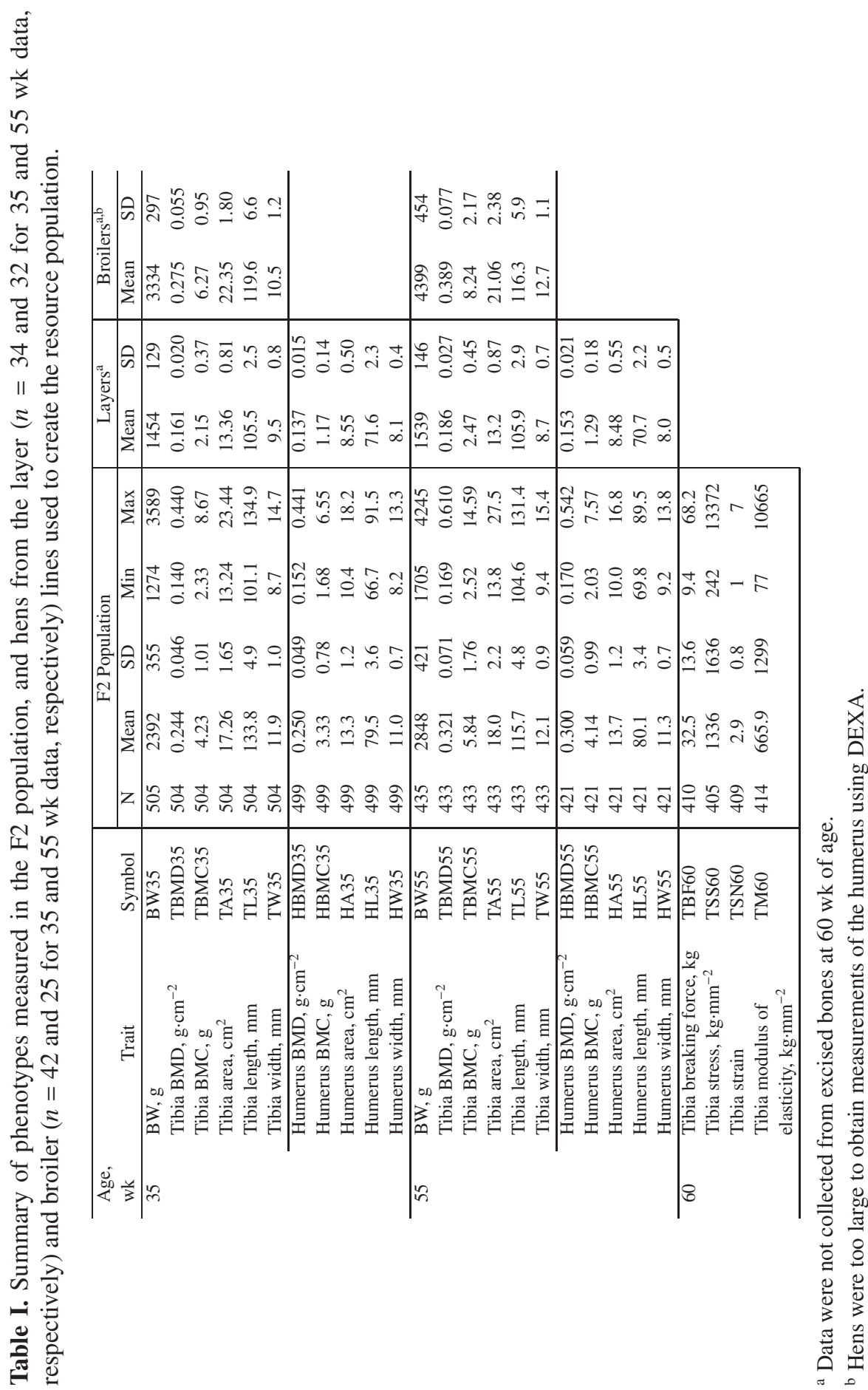


Table II. Summary of microsatellite markers genotyped in the F2 population.

\begin{tabular}{|c|c|c|c|c|c|}
\hline $\begin{array}{l}\text { Linkage } \\
\text { group }\end{array}$ & $\begin{array}{c}\text { Number of } \\
\text { markers used }\end{array}$ & $\begin{array}{c}\text { Genome } \\
\text { coverage } \\
(\mathrm{cM})\end{array}$ & $\begin{array}{c}\text { First } \\
\text { marker }^{\mathrm{a}}\end{array}$ & $\begin{array}{c}\text { Last } \\
\text { marker }^{\mathrm{a}}\end{array}$ & $\begin{array}{c}\text { Average } \\
\text { marker } \\
\text { informativeness }\end{array}$ \\
\hline 1 & 16 & 539 & MCW0168 & MCW0107 & 0.46 \\
\hline 2 & 15 & 461 & $A D L 0228$ & $M C W 0157$ & 0.57 \\
\hline 3 & 10 & 289 & MCW0141 & ROSO305 & 0.45 \\
\hline 4 & 11 & 242 & $A D L 0143$ & LEIO073 & 0.68 \\
\hline 5 & 7 & 198 & LEIO116 & $A D L 0298$ & 0.57 \\
\hline 6 & 3 & 36 & $A D L 0040$ & $A D L 0142$ & 0.56 \\
\hline 7 & 8 & 135 & LEIO064 & ADL0169 & 0.59 \\
\hline 8 & 5 & 93 & ABR0322 & MCW0351 & 0.48 \\
\hline 9 & 4 & 100 & ADL0191 & MCW0134 & 0.56 \\
\hline 10 & 4 & 114 & MCW0228 & $A D L 0112$ & 0.69 \\
\hline 11 & 3 & 90 & LEIOI43 & MCW0230 & 0.61 \\
\hline 12 & 4 & 65 & ADL0372 & MCW0332 & 0.48 \\
\hline 13 & 3 & 44 & $A D L 0147$ & MCW0104 & 0.55 \\
\hline 14 & 3 & 60 & $A D L 0200$ & $A D L 0263$ & 0.71 \\
\hline 15 & 3 & 61 & ADL0206 & MCW0080 & 0.75 \\
\hline 16 & 1 & - & LEIO258 & - & 0.97 \\
\hline 17 & 2 & 32 & HUJ002 & ADL0202 & 0.48 \\
\hline 18 & 3 & 47 & MYHE & MCW0219 & 0.51 \\
\hline 19 & 2 & 27 & MCW0094 & MCW0287 & 0.58 \\
\hline 23 & 2 & 86 & $A D L 0262$ & LEI0090 & 0.60 \\
\hline 24 & 1 & - & ROS0302 & - & 0.62 \\
\hline 26 & 2 & 36 & MCW0209 & LEIO074 & 0.60 \\
\hline 27 & 3 & 53 & MCW0300 & $A D L 0376$ & 0.52 \\
\hline 28 & 1 & - & ABR0341 & - & 0.79 \\
\hline E26 & 1 & - & GCT0037 & - & 0.50 \\
\hline E47 & 1 & - & ADL0034 & - & 0.62 \\
\hline E50 & 1 & - & GCT0004 & - & 0.65 \\
\hline E54 & 1 & - & ROS0334 & - & 0.19 \\
\hline
\end{tabular}

${ }^{a}$ All markers are included in Comprehensive Mapping Kit \#7 supplied by the US Poultry Genome Coordinators (http://poultry.mph.msu.edu).

${ }^{\mathrm{b}}$ Marker informativeness was calculated using QTL Express, following methods described by Knott et al. (1998).

Nine QTL tests surpassed the 5\% chromosome-wise level for at least one of the bone strength traits measured (tibia breaking force, stress, strain, and modulus of elasticity at $60 \mathrm{wk}$ of age; Tab. III). In general, the broiler allele at these QTL contributed to increased bone strength, and six of the QTL exhibited primarily dominant gene action. Four of the five chromosomes that contained 


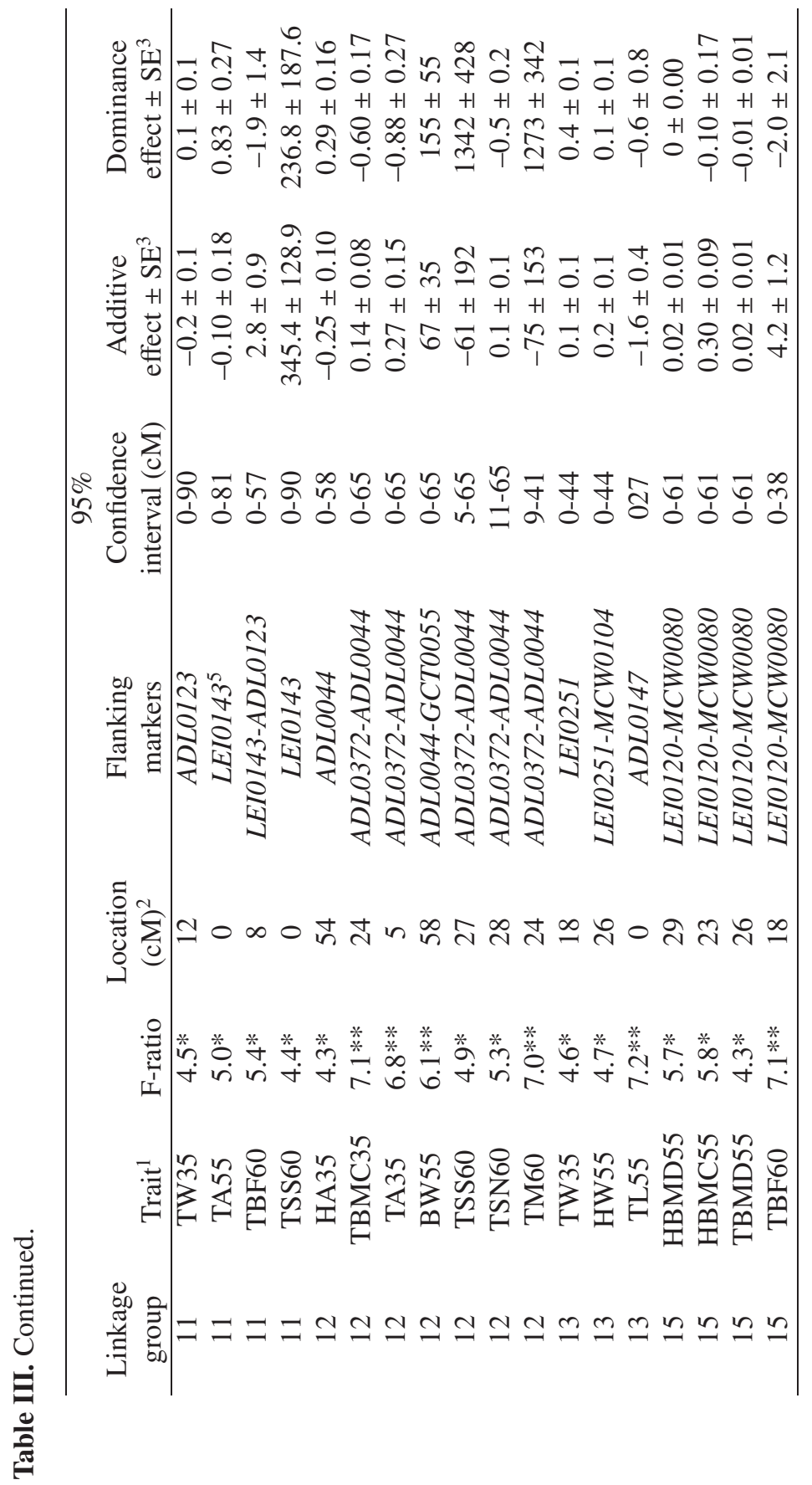




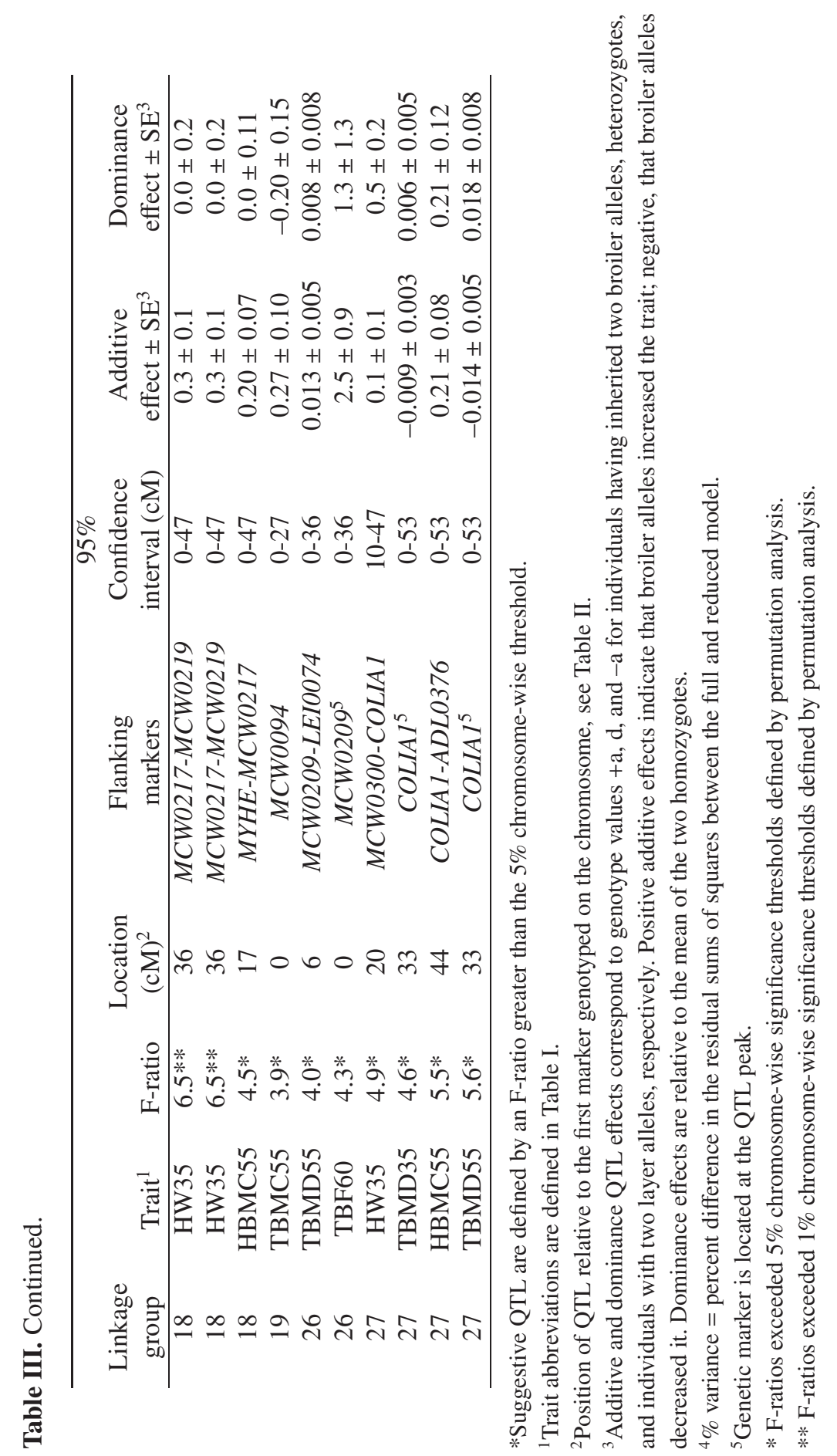


QTL influencing bone strength also contained QTL influencing one or more measurements of BMD or BMC.

A total of 20 suggestive (5\% chromosome-wise; Tab. IV) and 19 significant (5\% genome-wise; Tab. IV) QTL influencing bone size (area, length, or width of the tibia or humerus at 35 or $55 \mathrm{wk}$ ) was identified. Increased bone size was associated with the broiler allele for the majority of these QTL, although the effects of 11 of the suggestive QTL resulted primarily from dominant gene action.

Five QTL influencing BW at 35 or 55 wk of age were identified on chromosomes 4, 12, and 27, and four of these QTL (chromosomes 4 and 27) surpassed a $1 \%$ genome-wise significance threshold (Tab. IV). Each of the significant QTL is associated with increased BW from the broiler allele, while the suggestive QTL is primarily associated with dominant gene action.

\section{DISCUSSION}

The development of genetic maps [17], availability of highly polymorphic genetic markers [11], and statistical methodology appropriate for outbred populations [19] provide the tools needed to map complex traits in the chicken. A number of QTL mapping studies have been performed on crosses between genetically and phenotypically divergent lines of chickens. These studies have focused on identifying QTL responsible for body weight [39, 46, 47, 51, 52, 55], feed-efficiency [57], growth [7,20,27,55,57,62], carcass characteristics [12,23, 24,56], and egg traits [27, 39, 44, 54, 59]. Other researchers have investigated specific candidate genes potentially associated with variation in traits relating to bone integrity $[31,61]$. However, this is the first report of a genome scan focused on the identification of QTL influencing bone traits in chickens.

The significant difference in BMD phenotypes observed between layer and broiler lines was anticipated because these lines differ for multiple traits, including body weight. A significant positive phenotypic correlation between body weight and bone strength in chickens has been reported previously $[4,34,41]$, and was observed in the F2 resource population. However, adjusting for body weight did not remove the difference in BMD observed between the layer and broiler lines, suggesting there is a significant difference in BMD that is independent of body weight. The lack of difference in BMD at early ages (15 and $25 \mathrm{wk}$ ) likely reflects the earlier onset of sexual maturity and deposition of medullary bone in layer compared to broiler hens. 
M.A. Schreiweis et al.

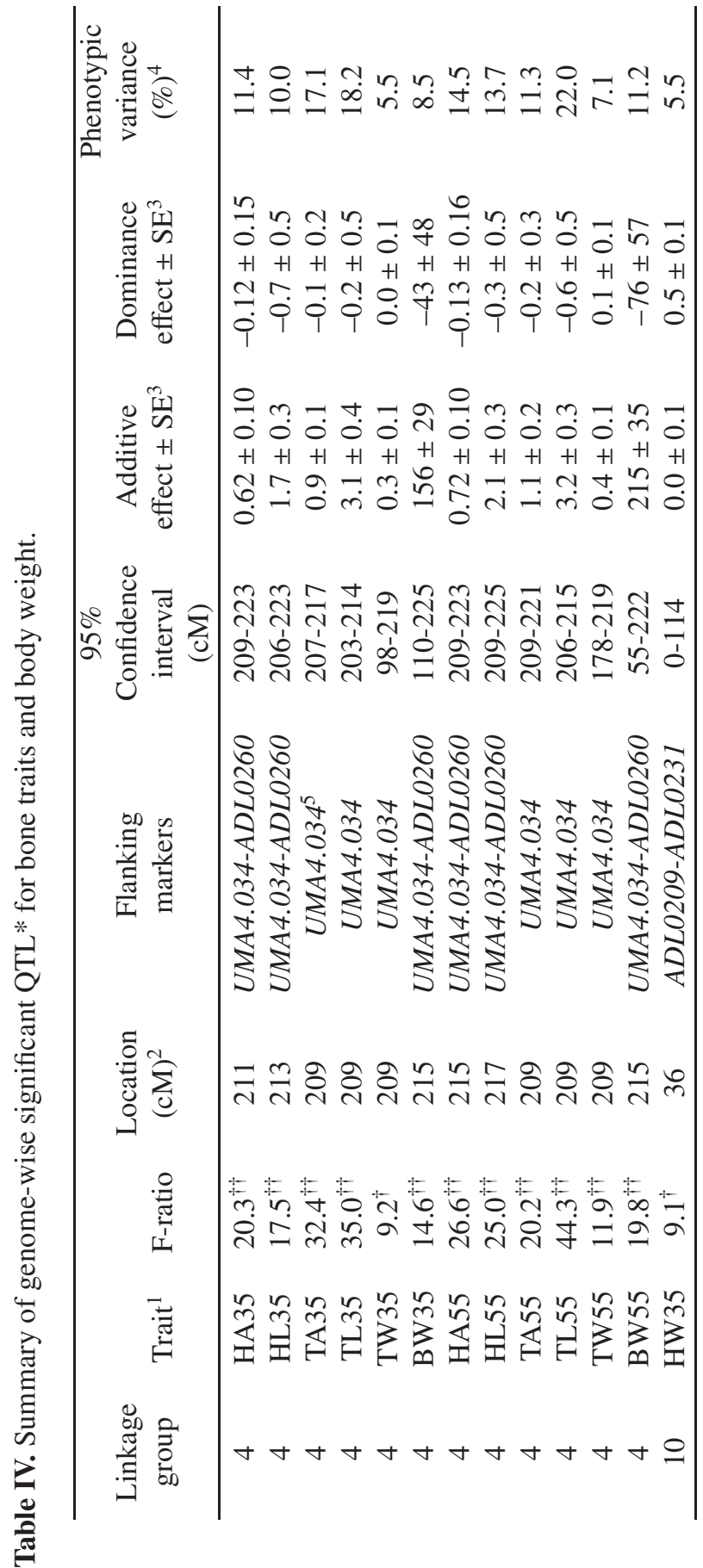




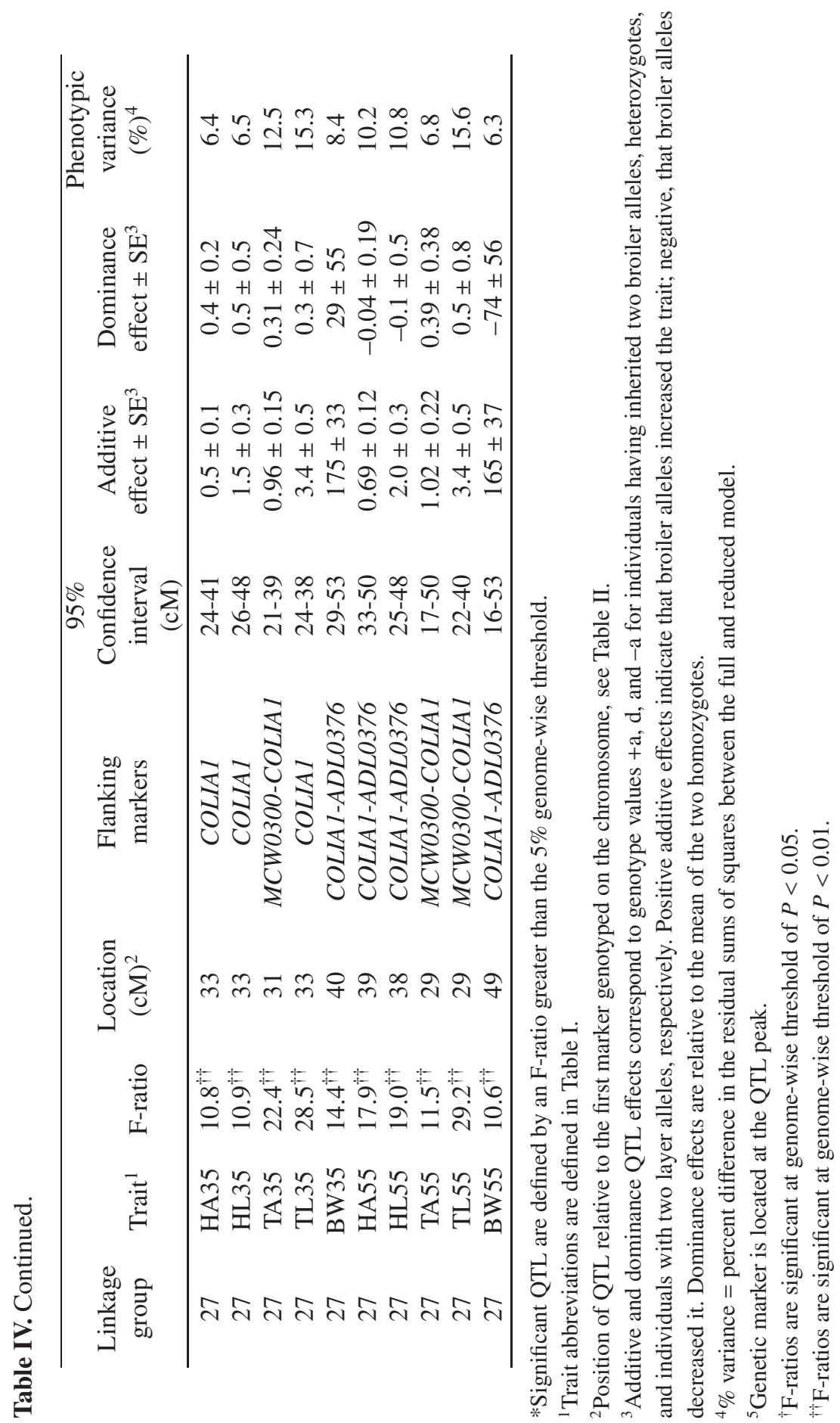


A total of 70 tests were deemed significant or suggestive in the genome scan. Of these QTL, 17 influenced one or more measurement of BMD or BMC at 35 or 55 wk of age, 39 influenced bone size, 9 affected bone strength measured in excised bones at $60 \mathrm{wk}$ of age, and 5 were associated with variation in BW at 35 or 55 wk. Previous studies also identified QTL for BW in chromosomal regions close to those found in this population $[39,46,54]$. Due to the number of traits evaluated in this study, consideration needs to be given to the issue of multiple testing. Significant QTL were defined based on genome-wise significance thresholds. As 26 traits were evaluated, 1.3 tests $(0.05 \times 26)$ were expected to be called significant by chance alone, as compared to the 23 QTL that were found to surpass the genome-wise significant threshold. Similarly, we considered 26 traits across 28 chromosomes for a total of 746 tests at the chromosome level. Our results identified 70 significant and suggestive QTL that surpassed the chromosome-wise significance threshold. Thus, it may be expected that approximately 36 of these 70 QTL represent false positive results.

The lack of identification of significant QTL for BMD and BMC traits in this population was surprising, given previous estimates for the heritability of traits relating to bone strength [4]. One factor that contributed to this result was the inclusion of BW and egg production as covariates in the analysis for BMD and BMC QTL. When analyses were completed with only BW as a covariate, a significant QTL was found on chromosome 4. When analyses were conducted without either covariate, a total of nine QTL influencing BMD and BMC surpassed the genome-wise significance threshold (chromosomes 3, 4, and 27; data not shown). However, QTL most likely to be effective at improving bone strength in laying hen populations without creating undesirable correlated responses in BW or egg production are the QTL that influence BMD and BMC independently of BW. Thus, only the QTL identified after accounting for variation in BW and egg production are presented. The identification of these QTL suggests it will be possible to improve bone strength while avoiding undesirable correlated changes in BW and egg production, but that progress based on the QTL characterized in this population may be slow.

It is important to recognize that unintentional differences in management were applied across hatches in this study. These differences include the feeding of a diet deficient in calcium for 12 days when hatches ranged in age from 30 to $44 \mathrm{wk}$, and variation in age at initiation of feed restriction (6 to $12 \mathrm{wk}$ ). Although hatch was included as a fixed effect in the analysis model, this would only account for differences in phenotypic means among hatches, and not account for potential genotype by hatch interactions. If such interactions exist, 
they would contribute to residual variance and reduce the power to detect QTL. This may partially contribute to the relatively limited number of significant QTL detected for BMD and BMC in this experiment, although it is difficult to know the true effect caused by the management differences.

The confidence intervals containing QTL identified in this study range from $9 \mathrm{cM}$ to complete chromosomes, and potentially contain hundreds of genes. However, important genes associated with calcium and bone metabolism are located within these confidence intervals and deserve mention as potential positional candidate genes for the QTL. Candidate genes on chromosome 4 include albumin, NF- $\kappa \mathrm{B}$ p50 precursor, and osteopontin $[48,50]$. Albumin is a plasma protein that accounts for $90 \%$ of the protein binding of calcium in blood [35]. Alterations in albumin concentration in the plasma due to changes in $\mathrm{pH}$ of blood can affect calcium homeostasis [6]. The NF- $\mathrm{KB}$ p50 precursor is a component of the signaling pathway that regulates formation, resorptive activity and survival of osteoclasts, or bone resorbing cells [25,30]. Osteopontin is a protein that is expressed and secreted by the osteoblast into the bone matrix [21]. The role of osteopontin in bone is not completely characterized; however, osteopontin facilitates osteoclast attachment to the bone matrix for bone resorption and binds hydroxyapatite, which makes up the mineral component of bone [36].

The QTL region on chromosome 2 containing the QTL for BMD of the tibia at $55 \mathrm{wk}$ of age includes the gene for bone morphogenetic protein 6 (BMP6) [16,49]. The BMP family is involved in differentiation of osteoblasts and chondrocytes during skeletal development [26, 37]. Another candidate gene, transforming growth factor- $\beta 2$ (TGF $\beta 2$ ), is located on chromosome 3 near the peak affecting BMD of the tibia at $35 \mathrm{wk}$ of age, as well as bone breaking force of the tibia. TGF $\beta 2$ influences bone and adipose cell differentiation $[1,6,8,53]$, and a polymorphism in the promoter of this gene has been associated with BMD and BMC of the tibia at $8 \mathrm{wk}$ in a chicken population derived from a cross between broiler sires and Leghorn dams [31].

In summary, several QTL influencing bone characteristics were identified in this study, contributing to an overall understanding of the genetic architecture regulating bone strength. Results of this study also indicate that although QTL influencing bone strength independently of BW and egg production exist, these QTL have a relatively small impact on overall phenotypic variation of traits related to bone strength, potentially limiting their application in marker-assisted selection programs. 


\section{ACKNOWLEDGEMENTS}

This research was supported by the National Research Initiative Grant No. 2002-35205-12629 from the USDA Cooperative State Research, Education, and Extension Service. The authors thank F.A. Haan and O.M. Van Dame for managerial assistance with the birds; Melissa Kopka and Pooja Talaty for their help generating the resource population and collecting data; the molecular biology lab personnel of Hy-line International including Amy McCarron, Kara Pinegar, and Karol Field for assistance with initial genotyping; Dr. Phillip SanMiguel for assistance with the ABI 3700; and Dr. Jim Arthur of Hy-Line who served as our industrial advisor.

\section{REFERENCES}

[1] Ahdloudj S., Lasmoles F., Holy X., Zerath E., Marie P.J., Transforming growth factor $\beta 2$ inhibits adipocyte differentiation induced by skeletal unloading in rat bone marrow stroma, J. Bone Min. Res. 17 (2002) 668-677.

[2] Arafa A.S., Harms R.H., Comparison of bone characteristics of hens of three different ages in cages and floor pens, Appl. Agric. Res. 2 (1987) 175-176.

[3] Belyavin C., Bone problems an increasing aliment in layers, World Poult. 11 (1995) 74-75.

[4] Bishop S.C., Fleming R.H., McCormack H.A., Flock D.K., Whitehead C.C., Inheritance of bone characteristics affecting osteoporosis in laying hens, $\mathrm{Br}$. Poult. Sci. 41 (2000) 33-40.

[5] Bonewald L.F., Transforming growth factor- $\beta$, in: Bilezikian J.P., Raisz L.G., Rodan G.A. (Eds.), Principles of Bone Biology, Academic Press, San Diego, CA, 2002, pp. 903-918.

[6] Broadus A.E., Mineral balance and homeostasis, in: Favus M.J. (Ed.), Primer on the metabolic bone diseases and disorders of mineral metabolism, American Society for Bone and Mineral Research, Washington D.C., 2003, pp. 105-111.

[7] Carlborg O., Kerje S., Schutz K., Jacobsson L., Jensen P., Andersson L., A global search reveals epistatic interaction between QTL for early growth in the chicken, Genet. Res. 13 (2003) 413-421.

[8] Chambers T.J., Regulation of the differentiation and function of osteoclasts, J. Pathol. 192 (2000) 4-13.

[9] Churchill G.A., Doerge R.W., Empirical threshold values for quantitative trait mapping, Genetics 138 (1994) 963-971.

[10] Crenshaw T.D., Peo E.R., Jr., Lewis A.J., Moser B.D., Bone strength as a trait for assessing mineralization in swine: A critical review of techniques involved, J. Anim. Sci. 53 (1981) 827-835.

[11] Crooijmans R.P.M.A., Dijkhof R.J.M., VanDerPoel J.J., Groenen M.A.M., New microsatellite markers in chicken optimized for automated fluorescent genotyping, Anim. Genet. 28 (1997) 427-437. 
[12] de Koning D.J., Windsor D., Hocking P.M., Burt D.W., Law A., Haley C.S., Morris A., Vincent J., Griffin H., Quantitative trait locus detection in commercial broiler lines using candidate regions, J. Anim. Sci. 81 (2003) 1158-1165.

[13] Fleming R.H., Whitehead C.C., Alvey D., Gregory N.G., Wilkins L.J., Bone structure and breaking strength in laying hens housed in different husbandry systems, Br. Poult. Sci. 35 (1994) 651-662.

[14] Green P., Falls K., Crooks S., Documentation for CRIMAP. Version 2.4, Washington School of Medicine, St Louis, MO, 1990.

[15] Gregory N.G., Wilkins L.J., Broken bones in domestic fowl: Handling and processing damage in end of lay battery hens, Br. Poult. Sci. 30 (1989) 555-562.

[16] Groenen M.A.M., Crooijmans R.P.M.A., Dijkhof R.J.M, Acar R., van der Poel J.J., Extending the chicken-human comparative map by placing 15 genes on the chicken linkage map, Anim. Genet. 30 (1999) 418-422.

[17] Groenen M.A.M., Cheng H.H., Bumstead N., Benkel B.F., Briles W.E., Burke T., Burt D.W, Crittenden L.B., Dodgson J., Hillel J., Lamont S., Ponce de Leon A., Soller M., Takahashi H., Vignal A., A consensus linkage map of the chicken genome, Genet. Res. 10 (2000) 137-147.

[18] Guinotte F., Nys Y., Effects of particle size and origin of calcium sources on eggshell quality and bone mineralization in laying hens, Poult. Sci. 70 (1991) 583-592.

[19] Haley C.S., Knott S.A., Elsen J., Mapping quantitative trait loci in crosses between outbred lines using least squares, Genetics 136 (1994) 1195-1207.

[20] Hamoen F.F.A., VanKaam J.B.C.H.M., Groenen M.A.M., Vereijken A.L.J., Bovenhuis H., Detection of genes on the Z-chromosome affecting growth and feathering in broilers, Poult. Sci. 80 (2001) 527-534.

[21] Horowitz M., Matrix proteins versus cytokines in the regulation of osteoblast function and bone formation, Calcif. Tissue Int. 72 (2003) 5-7.

[22] Hughes B.O., Appleby M.C., Increase in bone strength of spent laying hens housed in modified cages with perches, Vet. Rec. 124 (1989) 483-484.

[23] Ikeobi C.O.N., Woolliams J.A., Morrice D.R., Law A., Windsor D., Burt D.W., Hocking P.M., Quantitative trait loci affecting fatness in the chicken, Anim. Genet. 33 (2002) 428-435.

[24] Jennen D.G.J., Vereijken A.L.J., Bovenhuis H., Crooijmans R.P.M.A., Veenendaal A., van der Poel J.J., Groenen M.A.M., Detection and localization of quantitative trait loci affecting fatness in broilers, Poult. Sci. 83 (2004) 295-301.

[25] Karin M., Ben-Neriah Y., Phosphorylation meets ubiquitination: The control of the NF- $\mathrm{KB}$ activity, Ann. Rev. Immun. 18 (2000) 621-663.

[26] Katagiri T., Takahashi N., Regulatory mechanisms of osteoblast and osteoclast differentiation, Oral Dis. 8 (2002) 147-159.

[27] Kerje S., Carlborg O., Jacobsson L., Schutz K., Hartmann C., Jensen P., Andersson L., The twofold difference in adult size between the red junglefowl and White Leghorn chickens is largely explained by a limited number of QTLs, Anim. Genet. 34 (2003) 264-274.

[28] Knott S.A., Marklund L., Haley C.S., Andersson K., Davies W., Ellegren H., Fredholm M., Hansson I., Hoyheim B., Lundstrom K., Moller M., Andersson 
L., Multiple marker mapping of quantitative trait loci in a cross between outbred wild boar and large pigs, Genetics 149 (1998) 1069-1080.

[29] Knowles T.G., Broom D.M., Limb bone strength and movement in laying hens from different housing systems, Vet. Rec. 126 (1990) 354-356.

[30] Komarova S.V., Pilkington M.F., Weidema A.F., Dixon S.J., Sims S.M., RANK ligand-induced elevation of cytosolic $\mathrm{Ca}^{2+}$ accelerates nuclear translocation of nuclear factor $\kappa B$ in osteoclasts, J. Biol. Chem. 278 (2003) 8286-8293.

[31] Li H., Deeb N., Zhou H., Mitchell A.D., Ashwell C.M., Lamont S.J., Chicken quantitative trait loci for growth and body composition associated with transforming growth factor-B genes, Poult. Sci. 82 (2003) 347-356.

[32] Mandour M.A., Nestor K.E., Sacco R.E., Polley C.R., Havenstein G.B., Selection for increased humerus strength of cage reared broilers, Poult. Sci. 68 (1989) 1169-1173.

[33] McCoy M.A., Reilly G.A.C., Kilpatrick D.J., Density and breaking strength of bones of mortalities among caged layers, Res. Vet. Sci. 60 (1996) 185-186.

[34] Meyer G.B., Babcock S.W., Sunde M.L., An accurate in vivo technique for measuring bone mineral mass in chickens, J. Nutr. 96 (1968) 195-205.

[35] Portale A.A., Blood calcium, phosphorus, and magnesium, in: Favus M.J. (Ed.), Primer on the metabolic bone diseases and disorders of mineral metabolism, American Society for Bone and Mineral Research, Washington D.C., 2003, pp. 151-154.

[36] Roach H.I., Why does bone matrix contain non-collagenous proteins? The possible roles of osteocalcin, osteonectin, osteopontin, and bone sialoprotein in bone mineralisation and resorption, Cell Biol. Int. 18 (1994) 617-628.

[37] Rosen V., Wozney J.M., Bone Morphogenetic Proteins, in: Bilezikian J.P., Raisz L.G., Rodan G.A. (Eds.), Principles of Bone Biology, vol. 2, Academic Press, San Diego, CA, 2002, pp. 919-928.

[38] Rowland L.O., Jr. Harms R.H., Wilson H.R., Ahmed E.M., Waldroup P.W., Fry J.L., Influence of various dietary factors on bone fragility of caged layers, Poult. Sci. 47 (1968) 507-511.

[39] Sasaki O., Odawara S., Takahashi H., Nirasawa K., Oyamada Y., Yamamoto R., Ishii K., Nagamine Y., Takeda H., Kobayashi E., Furukawa T., Genetic mapping of quantitative trait loci affecting body weight, egg character and egg production in F2 intercross chickens, Anim. Genet. 35 (2004) 188-194.

[40] SAS ${ }^{\circledR}$ Institute, SAS ${ }^{\circledR} /$ STAT User's Guide. Release 6.03 ed., SAS ${ }^{\circledR}$ Institute, Inc., Cary, NC, USA, 1988.

[41] Schreiweis M.A., Orban J.I., Ledur M.C., Hester P.Y., The use of densitometry to detect differences in bone mineral density and content of live White Leghorns fed varying levels of dietary calcium, Poult. Sci. 82 (2003) 1292-1301.

[42] Schreiweis M.A., Orban J.I., Ledur M.C., Moody D.E., Hester P.Y., Effects of ovulatory and egg laying cycle on bone mineral density and content of live White Leghorns as assessed by dual-energy X-ray absorptiometry, Poult. Sci. 83 (2004) 1011-1019.

[43] Schreiweis M.A., Orban J.I., Ledur M.C., Moody D.E., Hester P.Y., Validation of dual-energy X-ray absorptiometry in live White Leghorns, Poult. Sci. 84 (2005) 91-99. 
[44] Schutz K., Kerje S., Carlborg O., Jacobsson L., Andersson L., Jensen P., QTL analysis of a Red Junglefowl $\times$ White Leghorn intercross reveals trade-off in resource allocation between behavior and production traits, Behav. Genet. 32 (2002) 423-433.

[45] Seaton D., Haley C.S., Knott S.A., Kearsey M., Visscher P.M., QTL express: mapping quantitative trait loci in simple and complex pedigrees, Bioinform. 18 (2002) 339-340.

[46] Sewalem A., Morrice D.M., Law A., Windsor D., Haley C.S., Ikeobi C.O.N., Burt D.W., Hocking P.M., Mapping of quantitative trait loci for body weight at three, six, and nine weeks of age in a broiler layer cross, Poult. Sci. 81 (2002) 1775-1781.

[47] Siwek M., Cornelissen S.J.B., Buitenhuis A.J., Nieuwland M.G.B., Bovenhuis H., Crooijmans R.P.M.A., Groenen M.A.M, Parmentier H.K., van der Poel J.J., Quantitative trait loci for body weight in layers differ from quantitative trait loci specific for antibody responses to sheep red blood cells, Poult. Sci. 83 (2004) 853-859.

[48] Smith E.J., Lyons L.A., Cheng H.H., Suchyta S.P., Comparative mapping of the chicken genome using the East Lansing reference population, Poult. Sci. 76 (1997) 743-747.

[49] Smith J., Bruley C.K., Paton I.R., Dunn I., Jones C.T., Windsor D., Morrice D.R., Law A.S., Masabanda J., Sazanov A., Waddington D., Fries R., Burt D.W., Differences in gene density on chicken macrochromosomes and microchromosomes, Anim. Genet. 31 (2000) 96-103.

[50] Suchyta S.P., Cheng H.H., Burnside J., Dodgson J.B., Comparative mapping of chicken anchor loci orthologous to genes on human chromosomes 1, 4 and 9, Anim. Genet. 32 (2001) 12-18.

[51] Tatsuda K., Fujinaka K., Genetic mapping of the QTL affecting body weight in chickens using a $F_{2}$ family, Br. Poult. Sci. 42 (2001) 333-337.

[52] Tatsuda K., Fujinaka K., Yamasaki T., Genetic mapping of a body weight trait in chicken, Anim. Sci. J. 71 (2000) 130-136.

[53] Thirunavukkarasu K., Miles R.R., Halladay D.L., Yang X., Galvin R.J.S., Chandrasekhar S., Martin T.J., Onyia J.E., Stimulation of osteoprotegerin (OPG) gene expression by transforming growth factor- $\beta$ (TGF- $\beta$ ), J. Biol. Chem. 276 (2001) 36241-36250.

[54] Tuiskula-Haavisto M., Honkatukia M., Vilkki J., de Koning D.J., Schulman N.F., Maki-Tanila A., Mapping of quantitative trait loci affecting quality and production traits in egg layers, Poult. Sci. 81 (2002) 919-927.

[55] van Kaam J.B.C.H.M., van Arendonk J.A.M., Groenen M.A.M., Bovenhuis H., Vereijken A.L.J., Crooijmans R.P.M.A., van der Poel J.J., Veenendaal A., Whole genome scan for quantitative trait loci affecting body weight in chickens using a three generation design, Livest. Prod. Sci. 54 (1998) 133-150.

[56] van Kaam J.B.C.H.M., Groenen M.A.M., Bovenhuis H., Veenendaal A., Vereijken A.L.J., Arendonk J.A.M., Whole genome scan in chickens for quantitative trait loci affecting carcass traits, Poult. Sci. 78 (1999) 1091-1099. 
[57] van Kaam J.B.C.H.M., Groenen M.A.M., Bovenhuis H., Veenendaal A., Vereijken A.L.J., Arendonk J.A.M., Whole genome scan in chickens for quantitative trait loci affecting growth and feed efficiency, Poult. Sci. 78 (1999) 15-23.

[58] Visscher P.M., Thompson R., Haley C.S., Confidence intervals for QTL locations using bootstrapping, Genetics 143 (1996) 1013-1020.

[59] Wardecka B., Olszewski R., Jaszczak K., Zieba G., Pierzchala M., Wicinska K., Relationship between microsatellite marker alleles on chromosomes 1-5 originating from the Rhode Island Red and Green-legged Partrigenous breeds and egg production and quality traits in $\mathrm{F}_{2}$ mapping population, J. Appl. Genet. 43 (2002) 319-329.

[60] Whitehead C.C., Fleming R.H., Osteoporosis in cage layers, Poult. Sci. 79 (2000) 1033-1041.

[61] Zhou H., Mitchell A.D., McMurtry J.P., Ashwell C.M., Lamont S.J., Insulin-like growth factor-1 gene polymorphism associations with growth, body composition, skeleton integrity, and metabolic traits in chickens, Poult. Sci. 84 (2005) 212-219.

[62] Zhu J.J., Lillehoj H.S., Allen P.C., van Tassell C.P., Sonstegard T.S., Cheng H.H., Pollock D., Sadjadi M., Min W., Emara M.G., Mapping quantitative trait loci associated with resistance to coccidiosis and growth, Poult. Sci. 82 (2003) 9-16.

To access this journal online: www.edpsciences.org 